\title{
Study on market mechanism for high penetration of renewable energy in power system in China
}

\author{
Fan Zhang ${ }^{1, *}$, Chenghui Tang ${ }^{1}$ \\ ${ }^{1}$ State Grid Energy Research Institute, Beijing, China
}

\begin{abstract}
This paper first introduces the current situation and background of China's renewable energy power generation, and analyzes the difficulties of renewable energy consumption in detail. The next section mainly introduces how China's electricity market mechanism adapted to renewable energy of high penetration. China's electricity market mechanism is further designed based on the existing market mechanism. These market mechanisms are divided into two stages. The first stage is that the spot market has not yet been established, and the second stage is the establishment of the spot market. In both stages, the design of a market mechanism to promote renewable energy accommodation is based on the national market.
\end{abstract}

\section{Introduction}

Recently, Major countries including the United States, China, Japan, Germany has made promises on carbon emission reduction. China made it clear that it will promote the revolution of energy production and consumption and build a clean, low carbon, safe and efficient energy system, which further pointed out the direction for the development of China's energy and power industry[1-2]. At the mean time, the power sector reform document stated that "starting from the implementation of the national strategy as a whole", "promote the transformation of the development mode of the power industry and the optimization of the energy structure, improve the quality and efficiency of development, and increase the proportion of renewable energy power generation and distributed energy system power generation in the power supply." This paper studies market mechanism that helps power system to improve flexibility and compatibility with high penetration of renewable energy[3].

\section{China's practice on renewable generation accommodation}

The State Grid of China implements the national renewable energy development strategy, takes various measures simultaneously, and actively supports the development of renewable energy. The SGCC actively explores the market-oriented consumption mode of renewable energy and carries out a large number of trading practices.

Based on the unified national electricity market, renewable energy transactions are organized in the national and provincial markets. The scale of renewable energy transactions between provinces is growing rapidly with the efficient use of UHV power transmission lines among provinces. In 2019, the renewable energy trading power among provinces was 71.8 billion kwh, with a year-on-year increase of $45.8 \%$. Through Tianzhong, Qishao, Lingshao and other transregional transmission channels, renewable energy from northwest and Northeast China was sent to North China, East China and central China, with a year-on-year increase of $48.7 \%$. Several means were taken to increase the trading volume of renewable energy, including Actively organize renewable energy to participate in market-oriented trading in provincial market, increasing the trading strength of renewable energy to replace coalfired power plants, etc. In 2019, the renewable energy substitution transaction is 31.8 billion kwh, which is twice the volume compared to the same period of last year[4].

Market mechanism of "price matching + surplus clearing" were built to expand the scope of trading, and coordinate the implementation of the optimal transmission price scheme, so as to promote more transactions. In 2019, a total of 6.961 billion kwh of renewable energy electricity was traded, effectively alleviating the contradiction of "three discards".

Market-oriented measures were also used to promote renewable energy consumption. To standardize the transaction varieties, organization methods and work processes of inter provincial transactions in the medium and long-term transaction cycle such as annual and above, monthly and within the month, establish the tracking evaluation and dynamic improvement mechanism of the implementation rules, and ensure that the renewable energy can be delivered successfully. Organize the preparation of China's first green power trading rules "Beijing Tianjin Hebei green power market trading rules (Trial)", and urge the North China Energy

* Corresponding author: zhangfan@sgeri.sgcc.com.cn 
Regulatory Bureau to officially print and issue in November this year[5].

\section{3 market mechanism design for promoting the development of renewable energy}

\section{1 mechanism of renewable generation participating in the inter provincial market}

In the case of limited local consumption capacity of renewable energy, the idea of renewable energy trans provincial consumption has aroused concern. There may be some complementarity between power load and renewable energy output among multiple regions. Effective use of this complementarity can significantly improve the overall renewable energy consumption capacity. In order to effectively promote the consumption of renewable energy, in addition to actively adopting technical means, we also need to fully consider the introduction of market-oriented mechanism. This section focuses on the analysis of the ways of renewable energy participating in the inter provincial market.

\subsubsection{The mechanism of renewable energy participating in the medium and long term market among provinces}

On the basis of clarifying the decomposition of priority generation plan, renewable energy enterprises participate in the market by means of inter provincial transfer transaction of renewable energy, inter provincial voluntary substitution transaction and priority substitution transaction between renewable energy and conventional power generation enterprises. When signing the relevant medium and long-term contracts, the power curve or curve decomposition principle must be stipulated. Before the opening of the spot market, if there is a deviation between the medium and long-term trading curve and the predicted power generation output, the adjustment can be made through market means such as transfer, replacement, repurchase transaction, etc. In the initial stage, if the deviation of power generation caused by renewable energy itself exceeds $20 \%$, the deviation settlement shall be carried out according to the regulations. Pilot renewable energy direct trading between provinces, low renewable energy and pumped storage electricity substitution trading. At the same time, each province should purchase the corresponding renewable energy in full according to the weight of renewable energy consumption responsibility.

\subsubsection{Mechanism of renewable energy participating in inter provincial spot market}

When renewable energy declare spot call price, when it is difficult to absorb in the day ahead and in the day, its surplus power generation capacity will participate in the inter provincial spot transaction, the transaction electricity will be settled by call price, and the consumption will be guaranteed through market mechanism such as priority call and priority substitution. When the renewable energy can not complete the medium and long-term trading plan in the implementation, the difference is replaced by the renewable energy of spot trading organization, which is regarded as the generation right transaction between the two.

Priority call: in the day ahead and day ahead call stage, when there is residual capacity in the transmission channel, renewable energy consumption demand in the power transmission Province, and the expected renewable energy consumption responsibility weight of the power receiving province can not be completed, under the premise of ensuring the safe operation of the power grid, the unused or newly added parts of the renewable energy in the power transmission province will be called in turn according to the price, and the power transmission curve formed in the early stage will be raised accordingly Until the peak transmission capacity reaches the upper limit of the available capacity of the transmission channel.

Priority replacement: in the day ahead and day transfer stage, when there is no space left in the export channel and the renewable energy conflicts with the conventional energy planned by the state, in order to ensure the renewable energy consumption, the output of the direct regulating thermal power unit can be reduced, and the renewable energy can be transferred first, so as to realize the power generation right replacement with the conventional energy.

In case of priority replacement, the renewable energy alternative electricity is settled according to the call (clearing) price, the receiving province is settled according to the original market price, and the replaced conventional energy unit is compensated according to the difference between the original market price and the renewable energy call (clearing) price. If the difference is negative, no compensation will be made as shown in following table.

Table 1. An overview of the characteristics of inter provincial market

\begin{tabular}{|c|c|c|}
\hline characteristic & $\begin{array}{c}\text { Inter provincial } \\
\text { unified market } \\
\text { model }\end{array}$ & $\begin{array}{c}\text { Inter provincial } \\
\text { joint market } \\
\text { model }\end{array}$ \\
\hline $\mathbf{1}$ & $\begin{array}{c}\text { The internal } \\
\text { trading of the } \\
\text { sub market is } \\
\text { carried out in a } \\
\text { unified way. }\end{array}$ & $\begin{array}{c}\text { Joint clearing of } \\
\text { medium and long } \\
\text { term and day ahead } \\
\text { spot markets in all } \\
\text { provinces }\end{array}$ \\
\hline characteristic & $\begin{array}{c}\text { Sub markets are } \\
\text { dominated by } \\
\text { medium and } \\
\text { long-term }\end{array}$ & $\begin{array}{c}\text { Joint clearing can } \\
\text { start from quantity } \\
\text { coupling, Further } \\
\text { transition to } \\
\text { transactions }\end{array}$ \\
& puantity \\
& pricecoupling, \\
\hline
\end{tabular}

Considering the randomness and intermittence of renewable energy output, combined with the short-term and ultra short-term prediction of renewable energy, this paper improves the design of day ahead and day ahead 
spot market, promotes the consumption of renewable energy, and realizes the efficient allocation of resources and the safe operation of power grid through the market mechanism. When the renewable energy consumption is difficult, the surplus power will participate in the inter provincial spot trading. We should establish a market mechanism such as preferential substitution to ensure consumption.

\section{2 mechanism of renewable generation participating in the provincial market}

\subsubsection{Medium and long term market in the province}

Reasonably determine the purchase and utilization hours of renewable energy security, and encourage renewable energy to enter the market beyond electricity consumption on the basis of ensuring the completion of purchase and utilization hours of renewable energy security. Renewable energy power generation can sign medium and long-term trading contracts with power users and power sales companies in the province, and provide power curve or curve decomposition principle. When the renewable energy is expected to be unable to complete the medium and long-term contract, the contract electricity quantity and curve can be adjusted through market mode (transfer, replacement and repurchase). At the initial stage, each province can avoid the settlement of partial power generation deviation caused by renewable energy itself according to the actual situation.

For the wind, light or low-cost grid projects, as a full guarantee purchase of priority power generation, if the wind and light are abandoned, the limited power generation will be approved as a transferable priority power generation plan.

\subsubsection{Provincial spot market}

Renewable energy enterprises, as price acceptors, only declare the next day's forecast generation curve before the day ahead market clearing, and guarantee the priority implementation in the process of day ahead market clearing; renewable energy enterprises can also declare the power price curve by themselves, and realize priority dispatching with the advantage of low variable cost. The medium and long-term contract part shall be settled according to the price agreed in the contract, and the deviation part between the actual implementation and the medium and long-term contract shall be settled according to the deviation formed in the spot transaction. The annual electricity quantity of renewable energy full guarantee purchase in each province shall be settled according to the benchmark electricity price; the electricity quantity of participating in market transaction shall be settled according to the market price. Renewable energy can carry out power generation right substitution transaction with conventional energy in the province, and conventional energy power generation enterprises can obtain certain compensation through substitution transaction.

\section{Market mechanisms for promoting renewable energy consumption}

\subsection{Propulsion Steps}

Within the framework of the unified national market, China's renewable energy resources will be allocated optimally on a large scale, mainly through participation in the electricity market and through medium and longterm transactions across provinces and regions. Through flexible short-term transactions, the volatility of renewable energy peak modulation issues can be eliminated. And it will gradually transit to a complete market system, including the medium and long-term market and spot market, achieving priority acceptance by taking advantage of the low marginal cost of renewable energy.

Short-term measures: establishing multiple types of medium and long-term interprovincial trading mechanisms to facilitate transmission of renewable energy across provinces and regions; improving interprovincial auxiliary service compensation and trading mechanism to promote all types of thermal power units for renewable energy to peak shaving; implementing renewable energy incremental spot market transactions across provinces and regions and making full use of channel space and receive-side peak shaving resources.

Relying on the existing interprovincial transmission channels, it is necessary to organize the "Three North" regions and the central and eastern regions to carry out interprovincial power rights trading, renewable energy and self-owned power generation rights trading, interprovincial renewable energy direct trading, interprovincial renewable energy outsourcing transaction, gradually liberalize cross-provincial power generation plan, guide renewable energy to bring its price advantage into full play, and realize priority delivery through market competition. At the same time, it is also critical to establish and improve the medium and long-term peak displacement exchange, low valley renewable energy and pumping electricity trading, emergency support transaction and other mechanisms, mobilize the enthusiasm of thermal power and pumped storage power stations for peak shaving of renewable energy, and ensure adequate peak-shaving resources for power grids. Constructing a trans-provincial and outward spot market for renewable energy increment and flexibly consuming abandoned wind and abandoned photoelectric quantity are also very important.

Medium and long-term measures: gradually transiting to the "medium and long-term market + spot market" model in national electricity market system, promoting renewable energy generation forecasting accuracy through market competition, achieving power balance in real-time market by using renewable energy and thermal power, utilizing the advantage of low marginal cost of renewable energy, and achieving renewable energy priority through market competition. 


\subsection{A market mechanism to promote renewable energy consumption}

For provinces where renewable energy has not yet been fully liberalized and with smaller market space,the transaction mode of inter-provincial renewable energy and the generation rights trade are adopted to develop outbound trade of the renewable energy. With the release of the inter-provincial power generation and electricity plan, the inter-provincial outbound trade of renewable energy and the direct trade between the renewable energy providers and users are developed. According to the actual situation in different places, we should carry out medium and long term peak load shifting trade, renewable energy and pumped capacity and emergency support transactions, flexibly regulate the external energy transmission of renewable energy. Transprovincial outbound cash market for increment of renewable energy is also developed.

At present, the transfer transaction of generation rights are mainly carried out in the provincial power market. With the pressure on renewable energy consumption gradually increased, the trade share of inter-provincial generation rights needs to be further expanded in order to promote the consumption of renewable energy electricity. When renewable energy enterprises in the province have reduced to the minimum operating power, they still face the risk of eliminating wind energy (solar energy) and power restriction, due to lack of consumption market. Meanwhile, thermal power enterprises in other provinces have the intention to reduce the operating power and space. Then renewable energy enterprises can give priority to the use of surplus power transmission channels to buy trans-provincial index of generating capacity of thermal power generation and replace their power generation in a market-oriented way. In this way, on the one hand it can promote renewable energy consumption, on the other hand it also gives regular energy some compensation. As a result, it can effectively balance the interests of all parties through the market.

\section{Conclusion}

In order to promote the consumption of renewable energy, the construction of China's power market should fully consider the fluctuation and intermittence of renewable energy output, build a market mechanism that adapts to the distribution and operation characteristics of renewable energy resources, well coordinates the market mechanism and generation plans, strengthen the interest coordination between market subjects, continuously carry out the innovation of trading mechanism, deeply develop the system potential, and promote the full consumption of renewable energy. Also there is urgent needs to establish a market-oriented mechanism to enhance the flexible adjustment ability of the system, promote deep peak shaving trading in spot pilot areas in the near future, promote the construction of auxiliary service market varieties such as FM and standby, and gradually realize the integration of peak shaving market and spot market in the medium and long term.

\section{Acknowledgment}

This work is supported by Science and technology project of State Grid Corporation of China "Strategic planning and market mechanism of green energy transformation with re-electrification as key"

\section{References}

1. SHU Yinbiao, ZHANG Zhigang, GUO Jianbo, et al . "Study on key factors and solution of renewable energy accommodation [J]" . ( Proceedings of the CSEE, 2017, 37(1): $1-8)$

2. LIU Yingqi, KOKKO Ari . Wind power in China: policy and development challenges $[\mathrm{J}]$. Energy Policy, 2010, 38(3): 5520-5529 .

3. HUA Xia, LUO Fan, ZHANG Jianhua, et al . "Feasibility analysis of trade mode promoting new energy consumption based on generation rights trade of self-generation power plant [J]" . ( Automation of Electric Power Systems,

2016 , 40(12) : 200-206 . DOI:

10.7500/AEPS20150413002.)

4. TANG Yi, ZHAO Lili, GUO Xiaojiang . "Impact of wind power penetration on angle transient stability of wind-thermal combined system [J]" .

(Automation of Electric Power Systems, 2013, 37(20): 34-40 . )

5. WANG Ningbo . "Study on wind power and thermal power transmission $[\mathrm{J}]$. " (Energy of China, 2010, 32(6): 18-20.) 